\title{
The Analysis of the Mechanism of Coordinated Development between the Road Transport Logistics Infrastructure and the Logistics Service
}

\author{
Xingang Weng, Liying Zhang \\ Beijing Wuzi University, Beijing, China \\ Email: bwzhangliying@163.com
}

Received 14 May 2015; accepted 19 June 2015; published 23 June 2015

Copyright @ 2015 by authors and Scientific Research Publishing Inc.

This work is licensed under the Creative Commons Attribution International License (CC BY).

http://creativecommons.org/licenses/by/4.0/

\section{c) (i) Open Access}

\begin{abstract}
Road logistics services can be developed quickly on the basis of perfect logistics infrastructure of road transport. And the development of road transport logistics infrastructure also needs to have the adverse effect of promoting the development of modern logistics. The article states the interaction relationship between logistics service and the road transport logistics infrastructure through theoretical method in this paper, which includes the support elements of the development of road logistics service, their interaction and the impetus of the coordinated development of both for the analysis of road transport logistics infrastructure and the coordinated development mechanism of the logistics service.
\end{abstract}

\section{Keywords}

Road Logistics Infrastructure, Logistics Services, Coordinated Development, the Mechanism

\section{Introduction}

In the process of economic development in our country, especially in the rapid development of e-commerce, the main contradiction of economic production is no longer quantity production, circulation logistics is the key to solving this contradiction. As the most important mode of transportation in logistics activities, the development of road logistics can be influenced by the logistics infrastructure construction [1]. Logistics infrastructure of road transport is one of the important organization carriers of logistics, logistics service and supply of transportation services are inseparable from the support and assurance of the transportation infrastructure, at the same 
time, the development of modern logistics service demand has played a certain role in promoting the development of road infrastructure.

\section{The Development Factors Support of Road Logistics Service}

\subsection{Trunk Road Elements}

Trunk road ensures the normal cargo transportation and communication between countries and regions, as well as ensures the normal operation of the comprehensive transportation system in countries and regions and is considered as the skeleton in the whole transportation system. Sea-land-air transportation means constitute the logistics service system, and road transport plays an important role in the cohesion of all of modes of transportation. So the transportation construction development is very important to improve the logistics service level. In the face of demand of modern logistics service which refers to the high efficiency, high quality of service requirements, direct transport channel plays a positive role that can be implemented to improve logistics efficiency and accelerate the turnover of the materials, thus to improve the comprehensive logistics service management system.

As is shown in the Table 1 and Figure 1, the development trend of logistics industry and road construction is consistent which relates to the logistics industry and road construction. And the Figure 2 shows that the influence of road infrastructure construction is close to the development of express industry [2] [3].

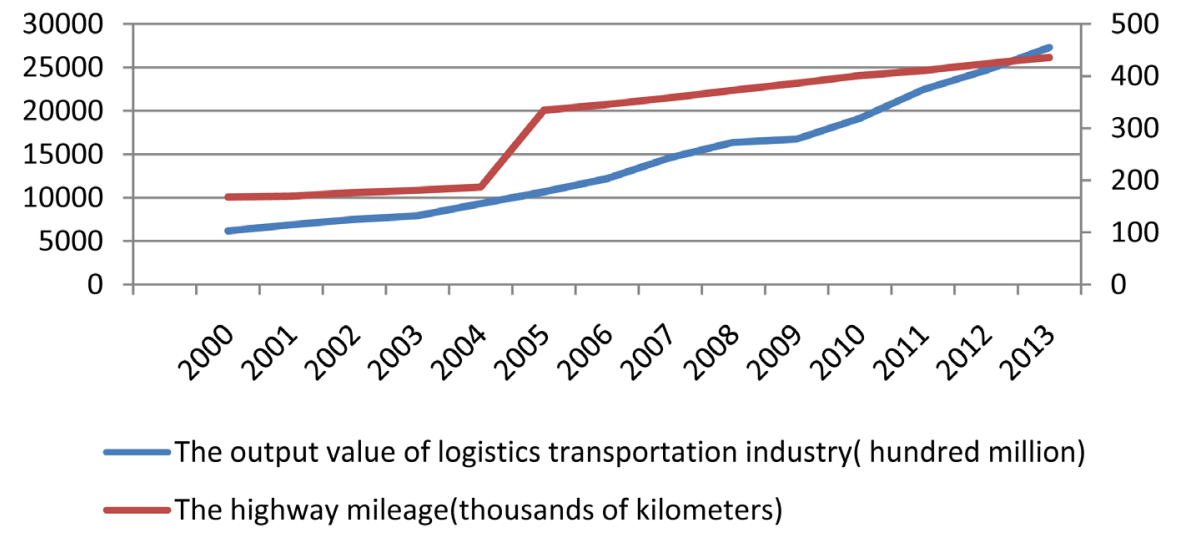

Figure 1. The development trend of logistics industry and road construction from 2000 to 2013.

Table 1. The data statistics of logistics industry and road construction from 2003 to 2013.

\begin{tabular}{ccc}
\hline Time & The output value of logistics (hundred million) & The highway mileage (thousands of kilometers) \\
\hline 2003 & 7913.2 & 180.98 \\
2004 & 9304.4 & 187.07 \\
2005 & 10666.2 & 334.52 \\
2006 & 12183.0 & 345.7 \\
2007 & 14601.0 & 358.37 \\
2008 & 16362.5 & 373.02 \\
2009 & 16727.1 & 386.08 \\
2010 & 19132.2 & 400.82 \\
2011 & 22432.8 & 410.64 \\
2012 & 24660.0 & 423.75 \\
2013 & 27282.9 & 435.6 \\
\hline
\end{tabular}




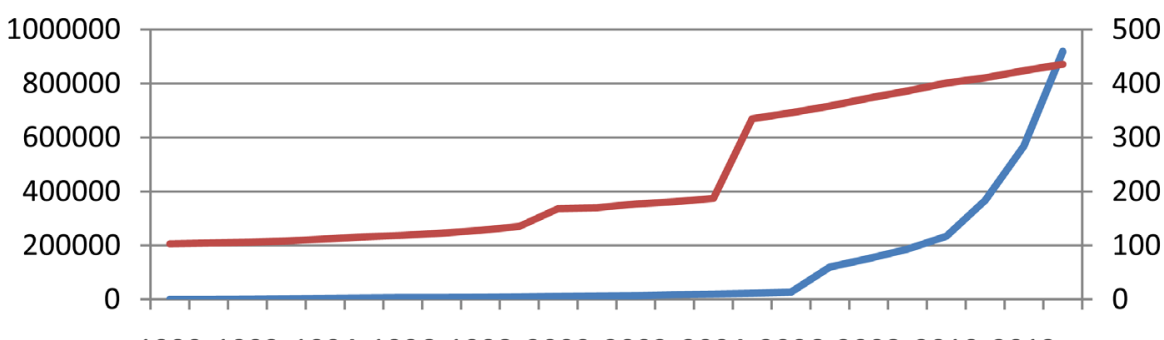

199019921994199619982000200220042006200820102012

The volume of express business(thousand pieces)

The highway mileage(thousands of kilometers)

Figure 2. The development trend of express business and road construction from 1990 to 2013.

\subsection{Road Network Elements}

Main traffic network, road network and urban and rural road network constitute the system of road network. Road network construction is also beginning to be large-scale and high speed, the access depth and road network capacity of road network are greatly improved, and so the average length of haul road has changed. Highway is suitable for short distance transportation, with the development of road infrastructure, our country's highway distance is increased six times as much from the initial $32 \mathrm{~km}$ to $187 \mathrm{~km}$ now by the period of reform and opening-up. It has a close relationship with the formation of the network. By foreign highway development level can know developed road network system can provide timely logistic service for road fast circulation channels. The formation of the road network also prompts network operating of logistics service.

\subsection{Hub Node Elements}

As the node facilities of logistics network of road transport, road freight hub and freight station field provide trading venues of various logistics activities and transportation loading, transshipment center of logistics activities such as organization, is also the place which links up multimodal transportation, therefore, the road freight hub and the yard is an important transport hub node which realize the regional economic circulation, goods circulation. These freight stations can form a comprehensive service station to provide logistics activities including distribution, logistics functions such as circulation of other logistics value-added services, formed the "gas station" of the logistics service through the connection of information network and the trunk road network.

\subsection{Information Elements}

Road transport logistics infrastructure have transport lines, logistics nodes realizing the function of goods distribution, and the matching information network, to provide convenience and guarantee for road logistics integration. Information network of road transport logistics provides information sorting, resources screening, directional release, timely feedback within the region and different regions. These factors of logistics information are integrated mainly through the logistics information platform. The platform construction of Logistics public information is an important characteristic of modern regional logistics development, and is also the important content that modern regional logistics network coordinates transportation management mode, which covers the logistics management, logistics nodes, logistics services, logistics enterprises and the supply chain information of upstream and downstream. Through the establishment of information network of road freight logistics, the freight information platform carry on the matching of supply and demand according to the sources of information on the net,, to realize matching of supply and capacity. Logistics service platforms provide information service network platform for road freight logistics, such as cainiao net, alibaba service platform.

\subsection{The Summary}

Road routes, hub node, and physical network consisted of the infrastructure and information network, which provided the material foundation for the development of logistics services. 


\section{The Analysis of Interaction between Road Transport Logistics Infrastructure and Logistics Service}

Logistics services is an advanced service mode and the whole service process to put the goods from one place to another in a way which is reasonable, accurate, timely, safety, quality. The whole process of services is related to the goods warehousing, transportation, processing and information, finance, insurance, and other links [4]. The transportation is an indispensable important component in the process of logistics services among them. Therefore, logistics services of this article focus on the service of road goods transport in the process of providing services such as cargo transport organization.

Road transport logistics infrastructure is one of the important organization carriers of logistics, logistics service and supply of transportation services without support and assurance of the transportation infrastructure is impossible. From the experience of developed countries such as Europe and the United States, quite a part of the logistics parks, logistics centers and distribution centers and other facilities are formed on the basis of transportation facilities to improve function and rational layout, integrating resources. To analysis from the relationship of transportation service and logistics service level, and the relationship between the transport services and transport facilities, the development of modern logistics is dependent on the support of transportation infrastructure, it needs that transport infrastructure's development adapts to the requirement of logistics development in an all-round way in such aspects as function, scale, structure, layout, etc.

\subsection{Road Transit Network Demand for Logistics Services}

Road transit network not only provides a material basis for logistics service, at the same time, there also exists mutual influence and interaction between road transit network and the logistics service demand. First of all, the road transit network is in the service of road transport of goods, and they implement requirements which include transport direction of cargo, shipping capacity distribution, and the area coverage of road line, at the same time, it also reacts on logistics service requirements such as goods transportation (as shown in Figure 3 and Figure 4).

If network construction density of road transport in the area is great, through quality is strong, the coverage areas of network are wide, and it has strong influence as well, it will make the scope of influence area of production dynamics enlarge the scale of production, thereby increasing the freight demand and demand structure of this area. When a new way of communication network is put into operation, cargo demand's redistribution happens with the increase of capacity that will also induce the new traffic [5]. In short, when road transit network is advanced, it will induce logistics service's demand, on the contrary, backward road transit network decreases the transport of goods about this region.

\subsection{The Influence of Road Transport Hub for Logistics Service Demand}

Gathering freight and distributing goods are the two major functions affecting cargo demand of road hub (as shown in Figure 5). As the hub node of all kinds of transport including the land, sea and air, and the network node of road transportation, road transport hub can realize resource integration which comes from different re-

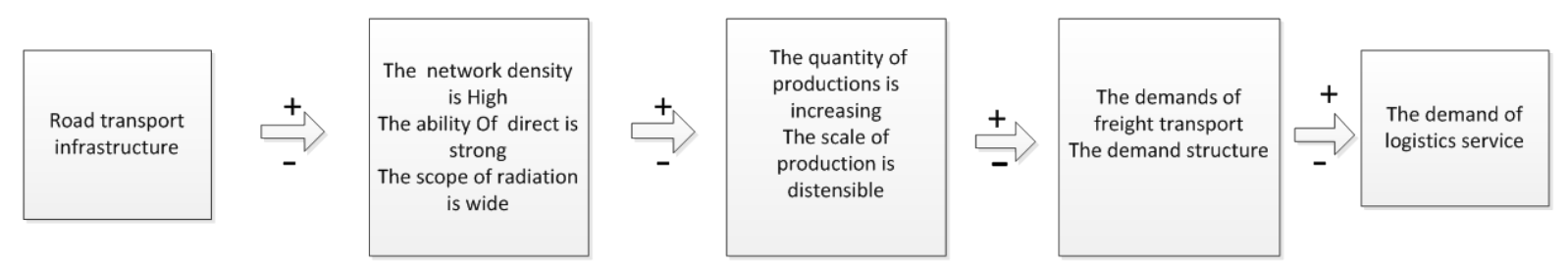

Figure 3. The mechanism of action between traffic network and logistics service demand.

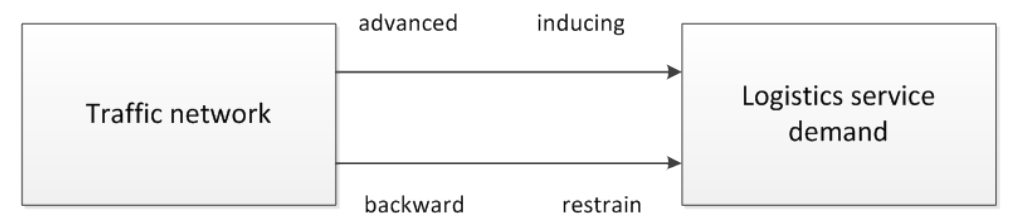

Figure 4. The interaction between traffic network and logistic service demand. 

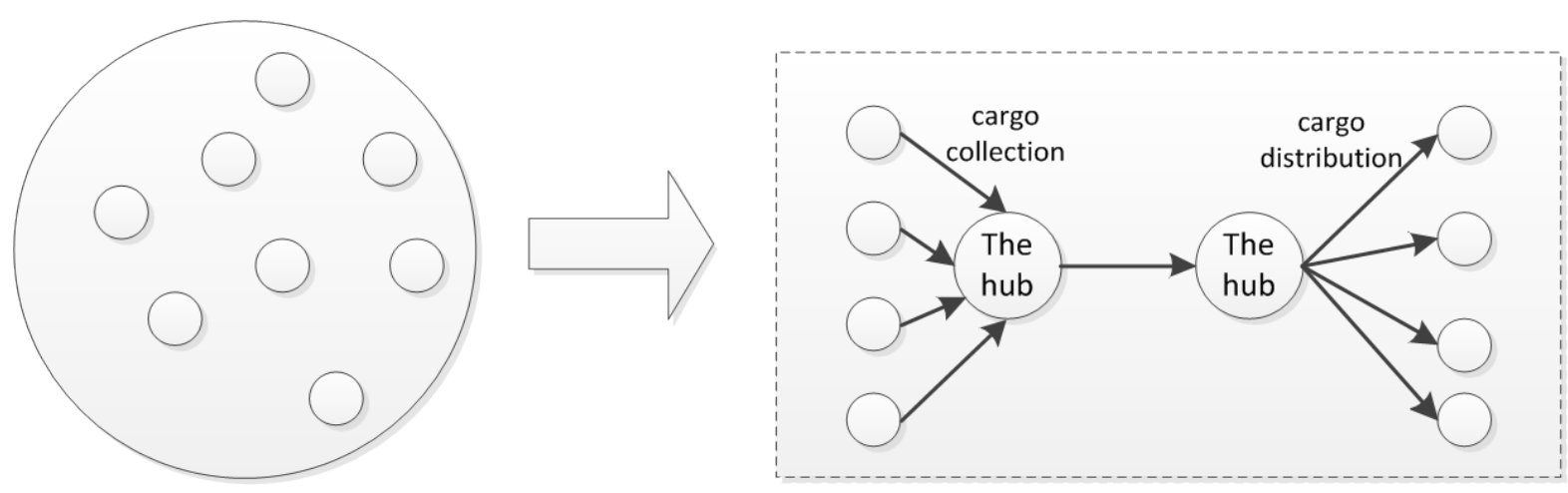

Figure 5. The collection and distribution of road traffic hub.

gions, different directions and different types, different modes of transportation, and realize quick docking, transferring, sorting, loading, and other functions, at the same time realize the dispersion transport within the radiation scope of the transport hub node so that it can help quickly realize normal production activity. Therefore the aggregation and divergent function of the road traffic hub affects the transport direction and the character of capacity of cargo transport demand (as shown in Figure 6).

\subsection{The Influence of Transportation Technology Demand to Logistics Services}

As a means of road logistics, transportation technique reflects the level of function of infrastructure, transportation technology affects road logistics service through the use of transportation technology to increase transport capacity, the speed of transportation and the level of transportation management, namely by improving the level of road logistics service (as shown in Figure 7).

\subsubsection{The Transport Capacity}

The nonstop degree of road transport routes and the loading levels of road transport vehicle are also affected by the level of transportation technology. Transportation technology also provides the necessary technical support for strengthening the goods circulation and the freight exchange. The transportation technology makes productivity achieve transfer from the origin of raw materials to the place of manufacture thus affecting the cargo demand structure. At the same time, there is no limit on the supply of goods, production place, and the weight of goods.

\subsubsection{The Scope of Transportation}

The improvement of transportation technology makes the transportation time and transportation efficiency, transportation area have greatly increase, and also makes transportation no longer restricted to the result of the cross-regional gap in time and space, which is one reason for the road transport distance increased. It provides technical support for long distance transportation.

\subsubsection{The Level of Transportation Management}

Through the application of transportation management technology, road transport line works closely with various transportation means that make comprehensive system of transport which gives priority to road transport realize the seamless connection, high strength coordination, reasonable division of various modes of transportation. Thus it enhanced the velocity and the through degree at the lowest cost of transportation, such as vehicle tracking system (GPS), vehicle route arrangement system (CVPS). These transportation management technologies make the transport management be automatic and scientific.

\subsection{The Development of Modern Logistics Service Requirements on the Infrastructure Network}

The ultimate purpose of perfect logistics service is to make the product circulation be smoother from supplier to consumer. As the change of era and the severe environment about global competition, enterprises can no 

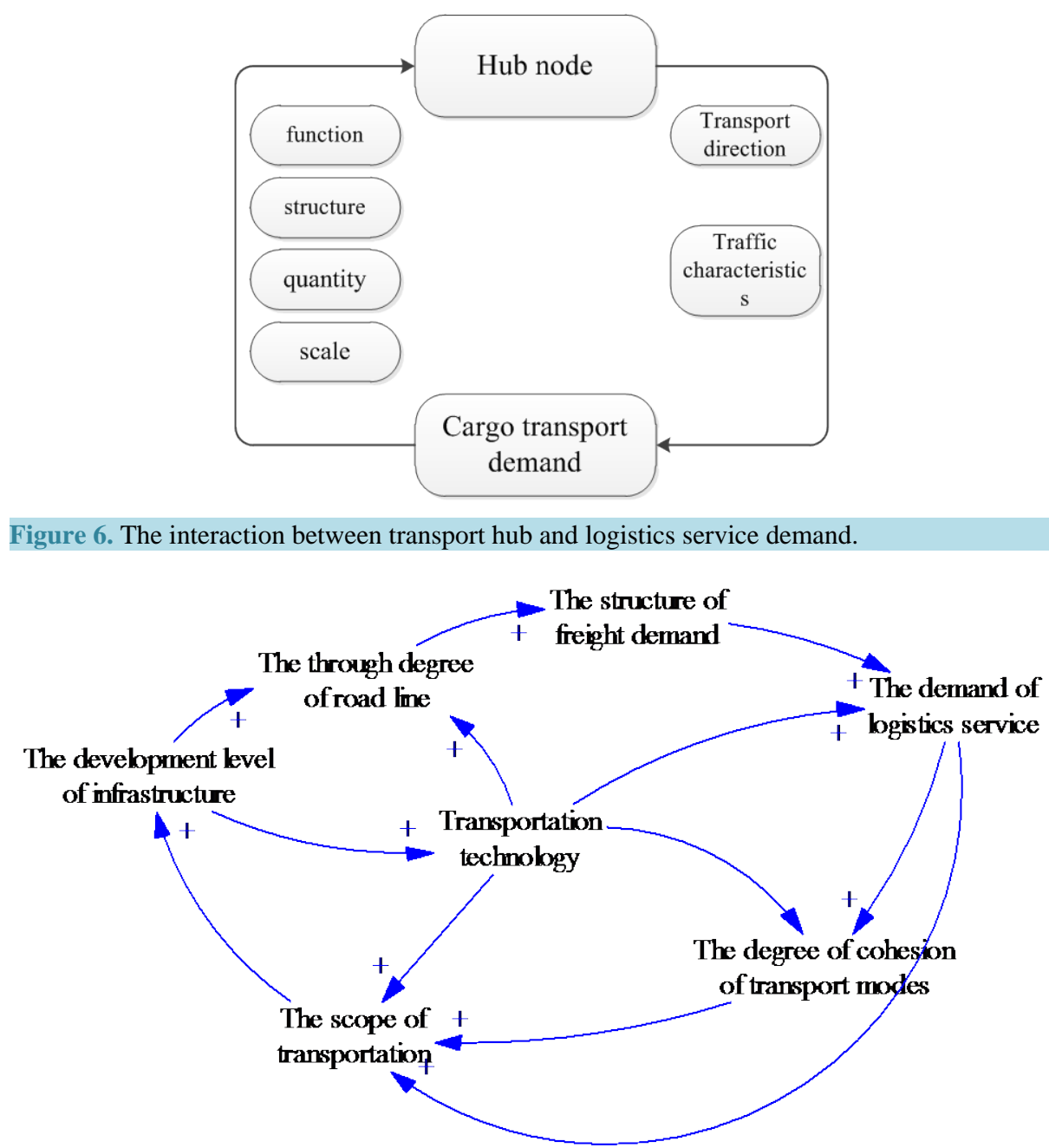

Figure 7. The interaction between logistics service requirements and transportation technology.

longer rely on themselves to get their own place in the competition, so they create the global supply chain. This form also accelerates the globalization of logistics activity and requests the service in a higher standardization. Logistics of globalization makes the miles of space become more and more close. The market demand promotes the development of the logistics service network layout. If these modern enterprises want to be in an impregnable position in the supply chain and in the build of logistics network and link, they should accelerate the system layout.

As the main way of service of logistics market, the logistics services of road transport should keep up with the trend of the times development course, and then construct the network services of road logistics.

It does not accord with the requirement of times development obviously that road transport resources on the premise of no network integration is managed by the organization of the enterprises in vulgar. The theory research of modern logistics network is gradually thorough along with the development of information network, organization network. The logistics enterprises begin to do the integration and optimization of logistics infrastructure resources, for example, the network integration of "aeroamphibious" infrastructure can produce good economic benefits. Market demand is the driving factor of all organizational restructuring. In order to meet the requirements of logistics market, the logistics enterprises do the recombination of organizational structure of logistics infrastructure, and network operations which can revitalize vitality and dynamic. Traditional and single competition of logistics service has gradually turned to the logistics service quality, process and method of competition. Enterprises in this environment need to change idea as soon as possible to cater to the demand of the market, so as to achieve a certain market share. 
Therefore, the network development of logistics service promotes the network development and operations of road transport infrastructure. Figure 8 shows that logistics infrastructure, logistics organization, logistics information should realize the network accordingly under the network request of modern logistics [6] [7].

\section{The Analysis of the Dynamic of the Coordinated Development between Road Logistics Infrastructure and Logistics Services}

\subsection{Put Forward the Logistics Policy System as the Intrinsic Motivation}

(1) Accelerating the modern logistics industry is the urgent requirement of modern economic transformation development.

As the main part of the third service industry of modern industrial structure, Logistics industry plays an important role in promoting our nation's competitiveness in the international environment, and the tilt adjustment to the third industry of our country's economic structure. "To develop the modern logistics industry" in the 11th five-year plan sets clearly the strategic targets and the key tasks of modern logistics industry in our country during the period of the "11th five-year plan", which includes enhancing the integration of logistics infrastructure, the construction of large logistics hub, the development of regional logistics center. In the eighteenth meeting the government has paid much attention to the development of service industry, and gives the higher demands and expectations to the development of logistics services, and regards the development of modern logistics service industry as an important strategic task to promote the development of our country's economy. In recent years, national policy have introduced about our country's logistics development policies and measures to promote the development of modern logistics. But from the point of objective conditions, due to China's logistics infrastructure foundation is weak, the degree of organization, the extent of the network connection is not enough, the lower shaky foundation leads to the unstable superstructure that doesn't makes the logistics services and infrastructure improve their logistics service level because of the lack of coordinated development. Therefore the government thinks it is reasonable and urgent to the coordinated development of road logistics service and road transport infrastructure.

(2) Road transport infrastructure is foundation assurance and the key role to promote the development of logistics industry.

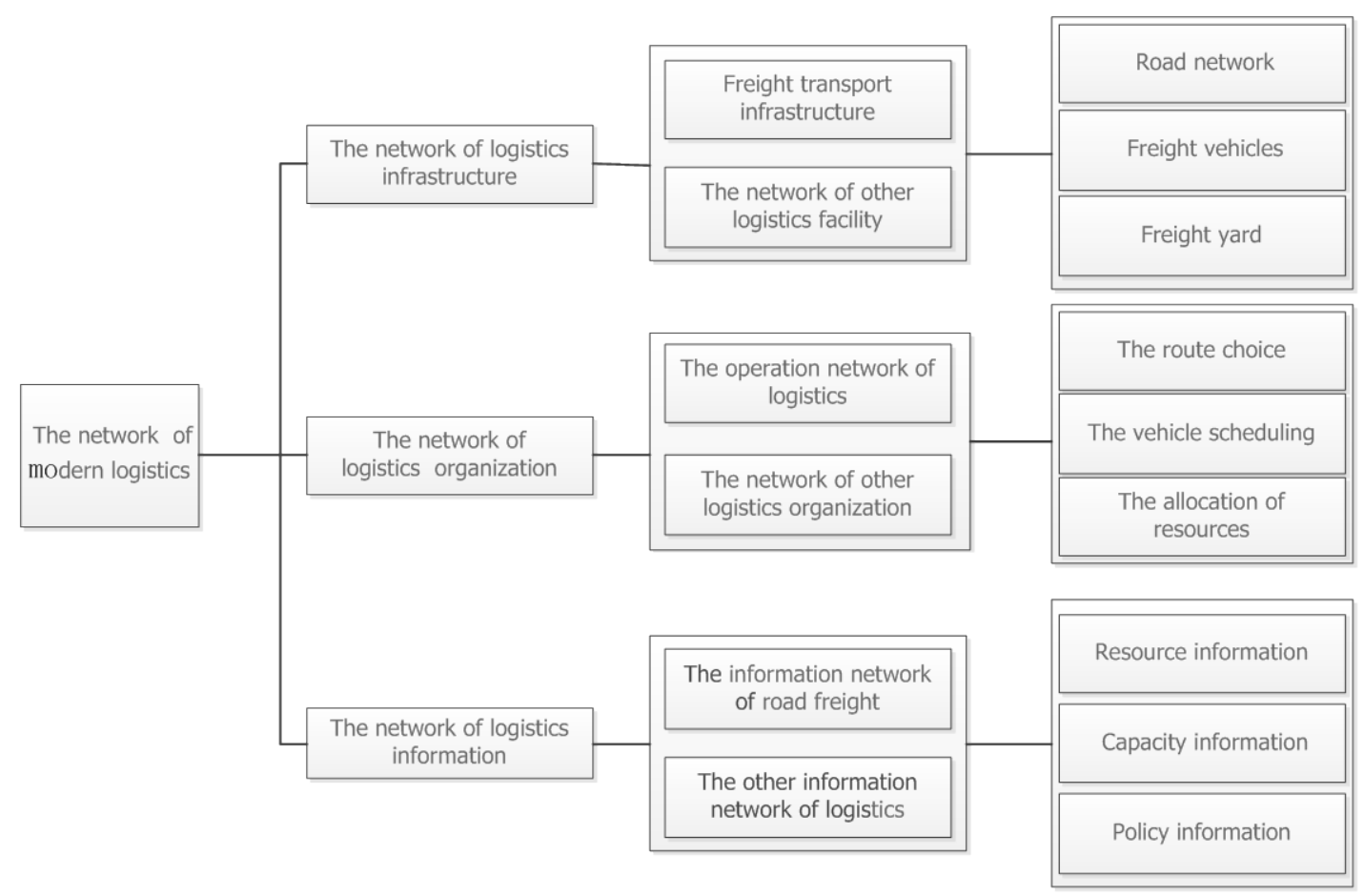

Figure 8. The development relationship between the development demand of modern logistics network and infrastructure networks. 
The ministry of communications puts forward “ The report of to promote the steady development of logistics industry in 2013" which says transportation infrastructure is the basis of the logistics links and carrier, and road transportation is the main way in several modes of transportation, is also the most important part of the logistics industry [7]. Traditional transportation industry transfers for the modern logistics industry gradually. Under the influence of modern logistics development, traditional freight enterprises also gradually turn to the modern logistics enterprise, and both of them will eventually realize the integration of development in the consolidation. The current situation summarizes that the level of logistics industry in our country is influenced by the road transport infrastructure, transport structure, the level of transportation organization, so the logistics industry in our country will continue staying in the primary stage of development on the basis of road transport for quite a long time. In 2013, with the continuous increase of network scale and technology level of transportation infrastructure, the whole service quality of transportation in our country is improved, and the capability of transportation service diversification gets further reinforce. The road transport acts as the dominant position in the logistics service, it must comply with the request of time development. So the road transport infrastructure and the logistics service must realize the synchronous development to strive to promote the healthy development of the modern logistics industry.

At present, it still exists many contradictions and problems in our country's transportation, thus promoting the collaborative development of logistics and infrastructure is the very real and urgent task the transportation industry faces.

\subsection{Treat the Development of Modern Logistics Informationization and Network Requirements as External Power}

The task of road logistics transport is to achieve the goods transform from the supplier to the demander. Road transport has advantages of good flexibility, convenience, which is suited for short distances transport, and has the highest proportion and is the most important way in the comprehensive transportation system. Modern logistics development cannot leave the road transport of goods, because the road transport of goods can promote the development of modern logistics, modern logistics at the same time provides a good opportunity and development momentum for the development of road transport of goods, especially for the development of the transport network.

Enterprises engage in the process of logistics activities and organization of express transportation, because the information degree is not perfect enough, each process of logistics activity has not formed seamless network convergence that leads to that logistics activities in the process of organizing exist the breakpoint and inefficiency [8]. With the development of information technology, logistics informationization has become the basis of the logistics industry and the inevitable requirement, information infrastructure of road transport construction decide the development direction of modern logistics and also be the development goals of logistics informationization.

The development trend of the intelligent logistics requires that logistics infrastructure also correspondingly provides the basis support of intelligence, information technology. Therefore, logistics service also needs information to help road transport infrastructure to provide logistics service at the same time. From the point of view of informationization, the coordinated development between road transport logistics infrastructure and the logistics service is inevitable which is the requirement of modern logistics development and is an necessary requirement and external driving force of the development of information of the modern logistics.

\subsection{Treat the Rapid Development of the Economy of Electronic Commerce as Fundamental Motivation}

In 2013, the growth of China's express delivery industry is in more than $50 \%$ for three years which is still in the high speed growth. Along with the rapid development of electronic commerce, express delivery form is optimistic and is becoming the new force of China's economy [9]. The data from statistical yearbook of 2014 pointed out that the logistics business income from the express delivery enterprises in our country, and postal enterprises totaled 254.78 billion yuan in 2013, the year-on-year growth was $28.6 \%$, accumulative total business completed 272.51 billion pieces; year-on-year growth was 33.8\% (as shown in Figure 9).

Since 2007, the proportion of the income of express delivery started rising. In 2013, the express income accounts for nearly half of our country's logistics industry revenue (as shown in Figure 10 and Table 2) [2] [3] [10]. 


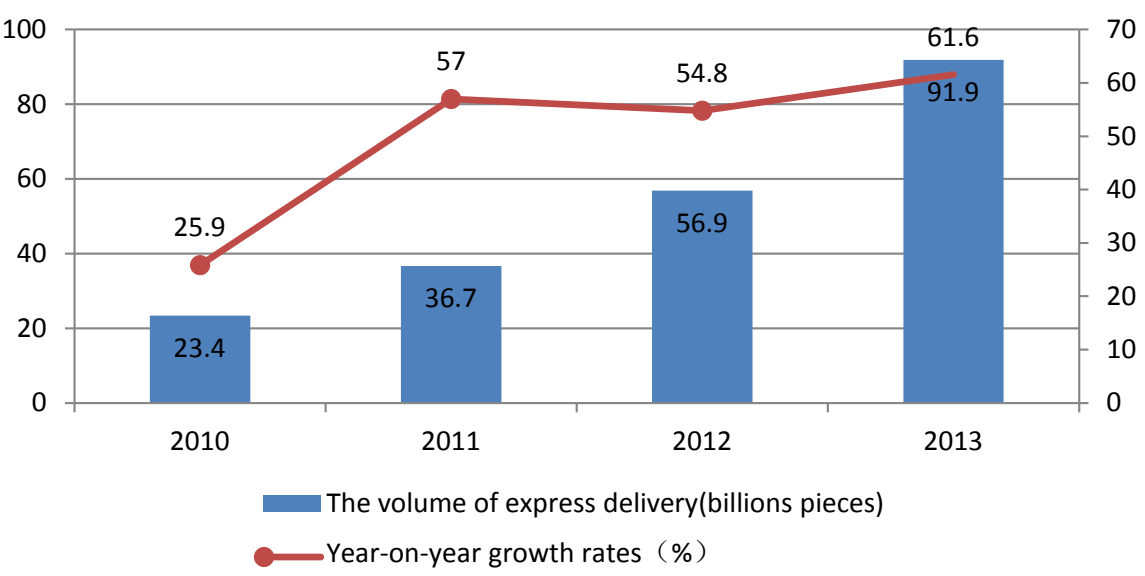

Figure 9. The volume of express delivery and year-on-year growth rate in the whole country.

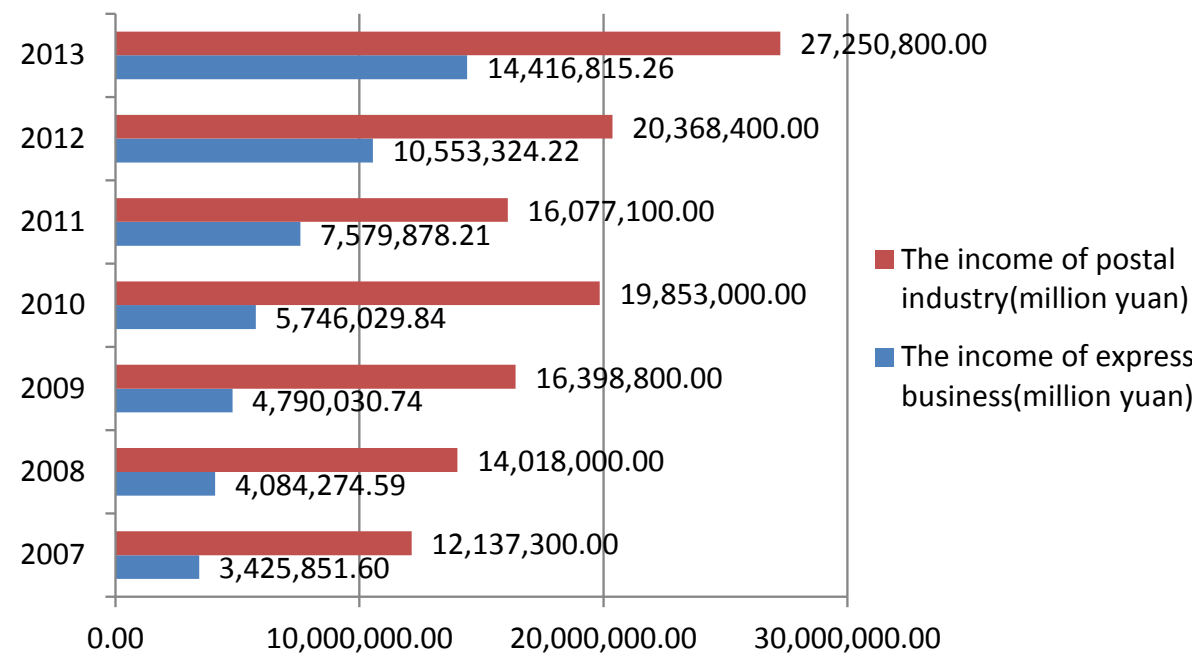

Figure 10. The comparison between postal industry income and express income from 2007 to 2013.

Table 2. The data of postal industry income and express income from 2007 to 2013. (unit :million yuan).

\begin{tabular}{cccccccc}
\hline & 2007 & 2008 & 2009 & 2010 & 2011 & 2012 & 2013 \\
\hline $\begin{array}{c}\text { The income of } \\
\text { express business }\end{array}$ & 3425851.60 & 4084274.59 & 4790030.74 & 5746029.84 & 7579878.21 & 10553324.22 & 14416815.26 \\
$\begin{array}{c}\text { The income of } \\
\text { postal industry }\end{array}$ & 12137300.00 & 14018000.00 & 16398800.00 & 19853000.00 & 16077100.00 & 20368400.00 & 27250800.00 \\
\hline
\end{tabular}

With the rapid development of electronic commerce, express income brings a huge economics benefit that needs solid logistics service as guarantee, and the material basis of the provider of this guarantee is logistics infrastructure. Having learned from the above, most of delivery is accomplished by the road transport, especially in short distance transportation, as well as the last one kilometer in the process of logistics distribution service. It is the most direct perceived service to the customers,, so the road transport logistics infrastructure decides the quality of logistics service and service ability at a great extent. Therefore, the rapid development of the electronic commerce and express industry has greatly promoted the harmonious development of road logistics infrastructure and logistics service.

\section{Conclusion}

Road logistics services can develop quickly only on the basis of perfect road logistics infrastructure. And the 
perfect development of road transport logistics infrastructure also needs the promotion of the development of modern logistics. Only understanding correctly the close relationship between logistics development and economic development in our country, the interaction between road transport infrastructure and logistics services, as well as the support effect on the development of electronic commerce from road logistics infrastructure, then we can guide the scientific construction and development of road logistics infrastructure to meet coordinated development in different areas between logistics and economic, then promote the healthy development of the logistics industry in our country finally.

\section{References}

[1] Dong, L.Y. (2009) The Research of Logistics Infrastructure Issues Based on the Traffic for the Sustainable Development of Regional. Central South University, Changsha.

[2] Wei, J. (2012) Road Cargo Transport Organization. Economic Management Press, 126-130

[3] The China Federation of Logistics and Purchasing (2014) China Logistics Yearbook (2014). China’s Wealth Publishing House, Beijing.

[4] The China Federation of Logistics and Purchasing (2013) China Logistics Yearbook (2013). China’s Wealth Publishing House, Beijing.

[5] The National Bureau of Statistics (2013) China Statistical Yearbook (2013). China Statistics Press, Beijing.

[6] iResearch Consulting Agency (2014) The Monitoring Data of China’s E-Commerce Market Monitoring Data. iResearch Consulting of 2014.

[7] Feng, X.H. (2011) The Theory and Method Research of the Demand Forecasting of Freight Transport Based on the Transport Channel. Chang'an University, Xi'an.

[8] Xi, J.P. (2011) The Research of the Development Model and the Operation Mechanism of Road Freight Network. Journal of Comprehensive Transportation, 2, 67-72

[9] Wang, M. (2014) The Theory and Practice of Development Planning of Logistics Industry. People’s Traffic Press, 312316.

[10] Yu, J.J. (2012) The Consideration of Road Transport Informatization Construction. Transport Business China. 